As part of the 50th birthday celebration, we are arranging to reprint 12 papers, the Editor's Choice, which have appeared in previous issues of the fournal. They have been chosen partly to illustrate the range and scope of the fournal over the years and partly because they are or were important in their day. More significantly, they have been chosen because they exemplify some of the best in scientific writing and can all be read with great pleasure and all who wish to communicate their observations, their ideas, or their enthusiasms would do well to study them and learn from them.

We will publish one paper each month through the year and they will appear in the order in which they were originally published.

\title{
Death rates of miners and ex-miners with and without coalworkers' pneumoconiosis in South Wales
}

\author{
by R G Carpenter, A L Cochrane, W G Clarke, G Jonathan, F Moore
}

(British Fournal of Industrial Medicine 1956;13:102-9)

I once heard someone who knew Archie Cochrane say of him that he was always going about doing good. I never knew him so I can't confirm that opinion from personal experience but his many publications bear this statement out, however. He is remembered by occupational physicians for his outstanding work among the Welsh coal miners for whom he had a great admiration and affection. With others at the MRC Pneumoconiosis Research Unit he set up epidemiological studies of chest diseases in miners which he pursued almost to the end of his life. He was a meticulous, almost obsessive worker, but his attention to detail showed that results from epidemiological studies could be achieved with the precision of those obtained in the laboratory if only one tried hard enough. He knew the problems of imperfect data as well as anyone but stressed that if "the problem is important, one is forced to see what can be deduced from the best material that is available."
Among epidemiologists, Cochrane will probably be remembered best for his campaigning on behalf of the randomised clinical trial and for his evaluation of health services that were published as Effectiveness and efficiency: random reflections on health services. This little book published in 1971 became an international best seller, much to his surprise and delight.

Cochrane's writings are always a pleasure to read and this paper is no exception. In it he examines the relation in miners between age, radiological category of pneumoconiosis, and expectation of life, concluding that simple pneumoconiosis is not associated with a decreased expectation of life at any age. At the time he was working this was a somewhat surprising observation.

Cochrane wrote his own obituary concluding that " $\mathrm{He}$ was a man with severe porphyria who smoked too much and was without the consolation of a wife, a religious belief, or a merit award but he didn't do too badly." We would concur with that. 